\title{
Article/Artigo
}

\section{Electromyography function, disability degree, and pain in leprosy patients undergoing neural mobilization treatment}

\author{
Função eletromiográfica, grau de incapacidade e de dor em portadores de hanseníase \\ submetidos à mobilização neural \\ Larissa Sales Téles Véras ${ }^{1,2,3}$, Rodrigo Gomes de Souza Vale ${ }^{2}$, Danielli Braga de Mello ${ }^{2,4}$, José Adail Fonseca de Castro $^{1,5}$, \\ Vicente Lima ${ }^{2}$, Alexis Trott ${ }^{6,7}$ and Estélio Henrique Martin Dantas ${ }^{2}$
}

\begin{abstract}
Introduction: This study aimed to evaluate the effect of the neural mobilization technique on electromyography function, disability degree, and pain in patients with leprosy. Methods: A sample of 56 individuals with leprosy was randomized into an experimental group, composed of 29 individuals undergoing treatment with neural mobilization, and a control group of 27 individuals who underwent conventional treatment. In both groups, the lesions in the lower limbs were treated. In the treatment with neural mobilization, the procedure used was mobilization of the lumbosacral roots and sciatic nerve biased to the peroneal nerve that innervates the anterior tibial muscle, which was evaluated in the electromyography. Results: Analysis of the electromyography function showed a significant increase $(\mathrm{p}<0.05)$ in the experimental group in both the right $(\Delta \%=22.1, \mathrm{p}=0.013)$ and the left anterior tibial muscles $(\Delta \%=27.7, \mathrm{p}=0.009)$, compared with the control group pre- and post-test. Analysis of the strength both in the movement of horizontal extension $(\Delta \%$ right $=11.7, p=0.003 / \Delta \%$ left $=27.4$, $\mathrm{p}=0.002)$ and in the movement of back flexion $(\Delta \%$ right $=31.1 ; \mathrm{p}=0.000 / \Delta \%$ left $=34.7$, $\mathrm{p}=0.000)$ showed a significant increase $(\mathrm{p}<0.05)$ in both the right and the left segments when comparing the experimental group pre- and post-test. The experimental group showed a significant reduction $(\mathrm{p}=0.000)$ in pain perception and disability degree when the pre- and posttest were compared and when compared with the control group in the post-test. Conclusions: Leprosy patients undergoing the technique of neural mobilization had an improvement in electromyography function and muscle strength, reducing disability degree and pain.
\end{abstract}

Keywords: Neural mobilization. Electromyography. Disability degree. Pain. Leprosy.

\section{RESUMO}

Introdução: Este estudo tem como objetivo avaliar o efeito da técnica de mobilização neural sobre a função eletromiográfica, grau de incapacidade e dor em portadores de hanseníase. Métodos: A amostra de 56 indivíduos portadores de hanseníase foi randomizada em: grupo experimental composto por 29 indivíduos submetidos ao tratamento com mobilização neural e grupo controle composto por 27 indivíduos submetidos ao tratamento convencional. Em ambos os grupos, foram tratadas as lesões nos membros inferiores. No tratamento com mobilização neural, o procedimento utilizado foi a mobilização das raízes lombossacrais e do nervo isquiático com viés para o nervo fibular, que inerva o músculo tibial anterior, o qual foi avaliado na eletromiografia. Resultados: Ao analisar a função eletromiográfica, observou-se aumento significativo $(\mathrm{p}<0,05)$ no grupo experimental em ambos os músculos tibiais anteriores, direito $(\Delta \%=22,1 ; \mathrm{p}=0,01)$ e esquerdo $(\Delta \%=27,7 ; \mathrm{p}=0,009)$, comparado ao grupo controle no pré e pós teste. Ao analisar a força no movimento de extensão horizontal $(\Delta \% \operatorname{dir}=11,7 ; \mathrm{p}=0,003 / \Delta \%$ esq $=27,4 ; \mathrm{p}=0,002)$ e no movimento de dorso flexão $(\Delta \%$ $\operatorname{dir}=31,1 ; \mathrm{p}=0,000 / \Delta \%$ esq=34,7; $\mathrm{p}=0,000)$, observou-se aumento significativo $(\mathrm{p}<0,05)$ em ambos os segmentos direito e esquerdo ao comparar o grupo experimental no pré e pós teste. $\mathrm{O}$ grupo experimental apresentou redução significativa $(\mathrm{p}=0,000)$ na percepção de dor e no grau de incapacidade ao comparar o pré e pós teste e na comparação com o grupo controle no pós teste. Conclusões: Pacientes submetidos à técnica de mobilização neural obtiveram melhora na função eletromiográfica e nos níveis de força muscular reduzindo o grau de incapacidade e dor. Palavras-chaves: Mobilização neural. Eletromiografia. Grau de incapacidade. Dor. Hanseníase.

1. Centro de Ciências da Saúde, Universidade Estadual do Piauí, Teresina, PI. 2. Laboratório de Biociências da Motricidade Humana, Universidade Federal do Estado do Rio de Janeiro, Rio de Janeiro, RJ. 3. Clínica Dermatológica, Hospital Getúlio Vargas, Teresina, PI. 4. Seção de Pós Graduação, Escola de Educação Física do Exército Brasileiro, Rio de Janeiro, RJ. 5. Laboratório de Doenças Parasitárias, Fundação Oswaldo Cruz, Rio de Janeiro, RJ. 6. Laboratório de Aspectos Moleculares Associados a Doenças Genéticas, Universidade do Oeste de Santa Catarina, Joaçaba, SC. 7. Genética Médica, Universidade Federal do Rio Grande do Sul, Porto Alegre, RS.

Address to: Prof. Alexis Trott. Lab. de Aspectos Moleculares Associados a Doenças Genéticas/UNOESC Av. Oiapoc 211, 89900-000 São Miguel do Oeste, SC, Brasil.

Phone: 55 49 3631-1075; Fax: $55493631-1002$

e-mail: alexistrott@hotmail.com

Received in 05/05/2011

Accepted in 29/07/2011

\section{INTRODUCTION}

Leprosy is an infectious and curable disease caused by the Hansen's bacillus, which has high infectivity and low pathogenicity, and this bacterium is responsible for the high immunogenic potential of this crippling disease ${ }^{1}$. The chronic granulomatous infection associated with leprosy primarily affects the skin and peripheral nerves; moreover, it is typically transmitted by the upper airways from person to person in a society where bacilliferous patients live without treatment ${ }^{2}$.

A common feature of the pathogenesis of leprosy is inflammation (in and around the nerve), which is driven in part by the immune responses in each area of the immunologic spectrum of leprosy; on the other hand, inflammation can also arise due to nonspecific inflammatory-related phenomena associated with inflammation, infection, and foreign bodies ${ }^{3}$. The mechanisms associated with inflammation still require further studies to be better understood, since the intercellular (and perhaps intracellular) oedema in the nerve trunk can lead to the compression of nerve fibres and, most likely, blood vessels, which can lead to ischaemia and further damage ${ }^{4}$.

Leprosy is a neurological condition that affects the peripheral nerves, reaching from the endings in the dermis to the nerve trunks, as a clinically mixed neuropathy; as a result, the sensitive nerve fibres, both motor and autonomic, are compromised, leading to altered sensitivity of thermal, painful, and tactile stimuli ${ }^{5}$

Electromyography (EMG) has been widely used in the evaluation of leprosy because the technique allows observation of overall muscle activity during specific activities and enables the quantification of the signal, which is often desirable to describe and compare the changes in the magnitude and pattern of the muscle response ${ }^{6}$. Moreover, the EMG examination has greater sensitivity and specificity for investigating the location and distribution of the neural pathways that act as the mode of nerve fibres involved and for identifying the neuropathological features ${ }^{7}$. 
Electromyography evaluation was used in a study by Correa et al. ${ }^{8}$ to identify the extent of peripheral involvement in patients with neuroschistosomiasis, even in patients in whom peripheral involvement was absent from the initial clinical neurological examination. The aim of the EMG evaluation was to describe the aspects of the initial EMG of neuroschistosomiasis patients and to compare the results with the data of motor development. Mahumud et al. ${ }^{9}$ used EMG to evaluate the relationship between the adverse neural tension and the electrophysiological involvement of the median nerve in patients with symptoms of carpal tunnel syndrome who underwent nerve conduction studies.

The technique of neural mobilization, also known as neurodynamics, is widely applied in clinical practice for the diagnosis and treatment of lesions of the peripheral nervous system and structures innervated by the peripheral nervous system; more specifically, this technique is characterized by the clinical application of the mechanics and physiology of the nervous system integrated with skeletal muscle function ${ }^{10}$.

The neural mobilization technique has been used as a resource for the differential diagnosis and treatment of plantar fasciitis in patients with neurogenic changes in the biomechanics of the feet ${ }^{11}$. Additionally, it has been used for the differential diagnosis of symptoms of the hand, especially in neurogenic disorders such as carpal tunnel syndrome and other diseases ${ }^{12}$.

For leprosy, the compression and entrapment of the swollen nerve (that is, the nerve hit by the bacillus that causes its degeneration) by neighbouring anatomic structures presents an inflammatory process that affects the surrounding tissues and results in characteristics of compression syndromes (impaired movement and mobility, loss of strength, paresthesias, and pain). This presents another aggravating factor of an extrinsic nature that should be considered in the mechanisms of peripheral nerve damage, especially for the neuritis of the leprosy reactions ${ }^{7}$.

As a result, the neural mobilization technique is presented as a non-pharmacological treatment option to reduce the degree of disability and pain and to promote an improved quality of life in people with leprosy. At the end of 2009 in Brazil, the prevalence of leprosy was 1.99 cases/10,000 inhabitants (38,179 cases under treatment), and the detection rate of new cases was 1.96 cases $/ 10,000$ inhabitants. Despite the reduction in prevalence from 19.54 to 1.99 patients per 10,000 population during the period between 1990 and 2009 , leprosy remains a public health problem in Brazil ${ }^{13}$. Leprosy is still present throughout the tropics and subtropics ${ }^{14}$. According to the World Health Organization (WHO), Brazil is among the most endemic countries for Hansen's disease in the world, with 37,610 new cases in 2009 ${ }^{15-16}$; consequently, the actions for elimination, problem solving, and continuous monitoring must be accelerated and intensified ${ }^{13}$. For the elimination of leprosy, as proposed by the $\mathrm{WHO}$, it is important to redefine the activities for controlling the disease ${ }^{17}$. The current strategy for controlling leprosy in Brazil is based on early case detection and treatment of all cases with multidrug therapy $(\mathrm{MDT})^{18}$.

Therefore, this study aimed to evaluate the effect of the neural mobilization technique on electromyography function, degree of disability, and pain in patients with leprosy.

\section{METHODS}

The research was quasi-experimental in design. The study sample was composed of leprosy patients treated by the Brazilian Unified Health System (SUS), in the City of Teresina, PI. The sample was selected in a non-probability random manner. The inclusion criteria were the following: all leprosy patients with lesions of the common peroneal nerve, patients with weakness in the anterior tibial muscle, patients treated or in treatment with MDT, patients with Grades I and/or II who had access to the physiotherapy services of the Center Mary Immaculate Linnaeus and the Araújo Hospital, and patients who were residents of Teresina, PI, or Timon, MA.

The sample size was calculated based on the number of leprosy patients with lesions of the lower limbs who had access to both physical therapy services (the Center Mary Immaculate Linnaeus and the Araújo Hospital) during the year 2007 (31 total), with a predicted error of 0.05 . The result was approximately 29 patients.

The sample of 56 individuals with leprosy was randomized into two groups: an experimental group, the neural mobilization group (NMG), composed of 29 individuals undergoing treatment with neural mobilization, and a control group (CG) composed of 27 individuals who underwent conventional treatment. The randomization was performed by generating the allocation sequence using the computer program GraphPad StatMate 1.0. Following randomization, the sequence numbers were kept in opaque envelopes, which were not closed, and the patients who passed the initial assessments were allocated to one of the groups.

Data collection was performed in three phases: a) diagnostic evaluation by assessing the degree of disability, the electromyography signal, and the perception of pain; b) intervention; and c) summative evaluation.

The assessment of the degree of disability (a) was based on the protocol of the Simplified Evaluation of Neural Function and Complications standardized by the Ministry of Health of Brazil ${ }^{19}$; the assessment was used to determine the degree of disability of an individual using the signs and symptoms from an assessment of the feet, their ability to adapt to different types of footwear, and the other necessary measures to prevent disabilities and deformities. The classification ranged from 0 to 2 . Grade 0 indicated no functional disability and the patient may have a protective sensation present throughout the plantar surface. Grade 1 indicated the loss of the protective sensation on the plantar surface. Grade 2 indicated the loss of the protective sensation on the plantar surface with other complications, ulcers and traumatic injuries, claws, foot drop, absorption, or contracture of the ankle ${ }^{19}$.

This evaluation was performed by collecting personal data from the patient, by examining the main areas affected by Hansen's bacillus, such as the face (nose and eyes) and the upper and lower limbs, by palpating the peripheral nerves of each segment, and by doing strength tests of the respective innervated muscle. In addition, the evaluation included inspection (to check for wounds, resorption, or the presence of mobile and rigid claws) and sensory evaluation of the hands and feet through the monofilament Semmes-Weinstein (aesthesiometer) on specific points of each member when compared with the contra-lateral side, with the patient's eyes closed, to report any sensations. 
The electromyography signal of the anterior tibial muscle (a) was evaluated using surface electrodes on the belly of the muscle. The placement of the electrodes followed those suggested by SENIAM (surface EMG for a non-invasive assessment of muscles) ${ }^{20}$, where the location of the electrode was shaved prior to clean-up abrasion with cotton soaked in alcohol and was subsequently marked (with pen) ${ }^{21}$. For the acquisition of the EMG data, the electromyography Miotool $400 \AA$, manufactured by Miotec Biomedical Equipment (Brazil), composed of a 4-channel system with a sampling frequency of 2000 $\mathrm{Hz}$ per channel, filter, raw and active sensors, was used.

For the assessment of pain (a), the visual analogue scale, a one-dimensional scale that assesses only one dimension of the pain experience, was used. This scale is simple, sensitive, and reproducible, allowing the continuous analysis of pain; for this scale, the range is a non-numerical straight line from no pain to the worst pain imaginable in the extreme ${ }^{22}$.

The intervention (b) consisted of eighteen assessments (six weeks) with a frequency of three times per week for both groups. The NMG began with the neurodynamic fibular test (NFT), which indicated the conditions that were affecting the front lateral leg and dorsal areas of the foot, and their movements consisted of plantar flexion/inversion of the ankle, foot, and toes, followed by raising the leg straight ${ }^{10}$.

The researcher kept the patient with hip extension and knee extension, as well as plantar flexion and inversion, and raised the patient's leg until the patient mentioned any symptoms of discomfort (pain, numbness, etc.); once this occurred, the test was positive. The extent and strength applied in the examination and treatment was conducted safely to minimize the risk of exacerbation of the symptoms or worsening of the disorders ${ }^{23}$. The range of motion (ROM) followed the parameters of the degrees of Maittland ${ }^{24}$, where degree II indicated the movement had great ROM, was free of tension or spasm, and did not cause pain.

Mobilization was performed in the lumbosacral roots, with the patient in a supine position, with legs crossed, the hip and knee bent at 90 degrees, and the leg-side mobilized by lying down; subsequently, the researcher held both legs, causing an oscillation in the back using the lower limbs as leverage, similar to the second protocol of Butler ${ }^{23}$. This has been demonstrated for ten to thirty oscillations per minute for three series ${ }^{10}$.

In addition, slider mobilization was used for the sciatic nerve biased to the peroneal nerve. This mobilization consisted of oscillatory movements of hip extension and knee extension, while maintaining the plantar flexion with inversion movement, as used in the $\mathrm{NFT}^{10}$. For this mobilization, the ROM was always in degree $\mathrm{II}^{25}$ to avoid stressful movements that may irritate the nervous system ${ }^{23,25}$. Both techniques were performed in three sets of thirty oscillating movements per minute.

To control the intensity of effort applied during the neural mobilization, the Perceived Exertion Scale-Perflex was used ${ }^{26}$. The NMG performed the intervention with a subjective perception of intensity of effort that reached forcing, between level 61 and 80 of the Perflex. The average perceptions were $67.5 \pm 7.3$, which characterized the neural mobilization as a maximum of the flexible exercises (flexibilizing).

Physical therapy in the control group was conventional, held in rehabilitation centres with flexibilizing and strengthening with the use of ankle exercisers or electrotherapy, such as functional electrical stimulation. The therapy was performed three times per week, and in addition to exercise, both flexibilizing and resistance were to be performed at home. After that, we had a (c) summative evaluation with the same variables and protocols.

The data were processed using SPSS 14.0 for Windows and are presented as mean, median, standard deviation, and minimum and maximum values. The normality and homogeneity of variance were verified through the Shapiro-Wilk and Levene tests, respectively. For the intra-group comparisons of the EMG variable, Student's t-test was used for dependent samples; for comparisons between groups, analysis of variance with repeated measures and multivariate analysis were used, both followed by the post hoc Scheffé test to identify possible differences. For the variables of strength, pain, and degree of disability, which have ordinal scales, we applied the Wilcoxon test for intra-group comparisons and the Kruskal-Wallis test followed by the Mann-Whitney test for the different groups. To analyse the frequency of the sensitivity variable, which has a nominal scale, we used the McNemar test for intra-group comparisons and the Chisquared test for intergroup comparisons. The study considered a value of $\mathrm{p}<0.05$ for statistical significance.

\section{Ethical considerations}

This research was performed in accordance with the Ethical Guidelines for Biomedical Research Involving Human Beings as stated in the principles in the Declaration of Helsinki ${ }^{27}$. The research project was also approved by the Ethics Committee of the State University of Piauí (UESP), Brazil, under the Protocol 120/2008.

\section{RESULTS}

It was observed that prior to intervention, the NMG and the CG had no significant difference between them $(p<0.05)$ in electromyography function and pain perception. The disability degree in both the NMG and the CG showed a median of 2.0.

After the intervention, we observed the analysis of variations in the pre- and post-tests in each of the groups studied in relation to the variables. Figure 1 presents the data of the electromyography signal in the experimental group and the control group.

In the analysis of the electromyography signal, there was a significant increase $(\mathrm{p}<0.05)$ in the NMG in both the right segment $(\Delta \%=22.1, \mathrm{p}=0.013)$ and left segment $(\Delta \%=27.7, \mathrm{p}=0.009)$ compared with the CG before and after testing. However, when the NMG was compared with the CG in the post-test, a significant difference was observed between the groups $(\mathrm{p}=0.006)$.

Figures 2 and 3 present the force data for the movements of horizontal extension and dorsal flexion, respectively, in the experimental group and the control group.

When the strength both in the movement of horizontal extension $(\Delta \%$ right $=11.7, \mathrm{p}=0.003 / \Delta \%$ left $=27.4, \mathrm{p}=0.002)$ and in the movement of back flexion $(\Delta \%$ right $=31.1 ; \mathrm{p}=0.000 / \Delta \%$ left $=34.7$, $\mathrm{p}=0.000)$ was analyzed, there was a significant increase $(\mathrm{p}<0.05)$ in both the right and the left segments compared with the NMG in the pre- and post-tests. When the NMG was compared with the CG in the post-test, there was also a significant difference between the groups $(\mathrm{p}=0.000)$.

Figure 4 presents the pain data for the experimental group and the control group. When comparisons were made between the pre- 
and post-test and between the CG and NMG post-tests, the NMG decreased significantly $(\mathrm{p}<0.05)$ in pain perception.

Figure 5 presents data on the degree of disability in the experimental group and the control group. By comparing the preand post-test and comparing the CG and NMG post-tests, it was observed that the NMG decreased significantly $(p<0.05)$ in the degree of disability.

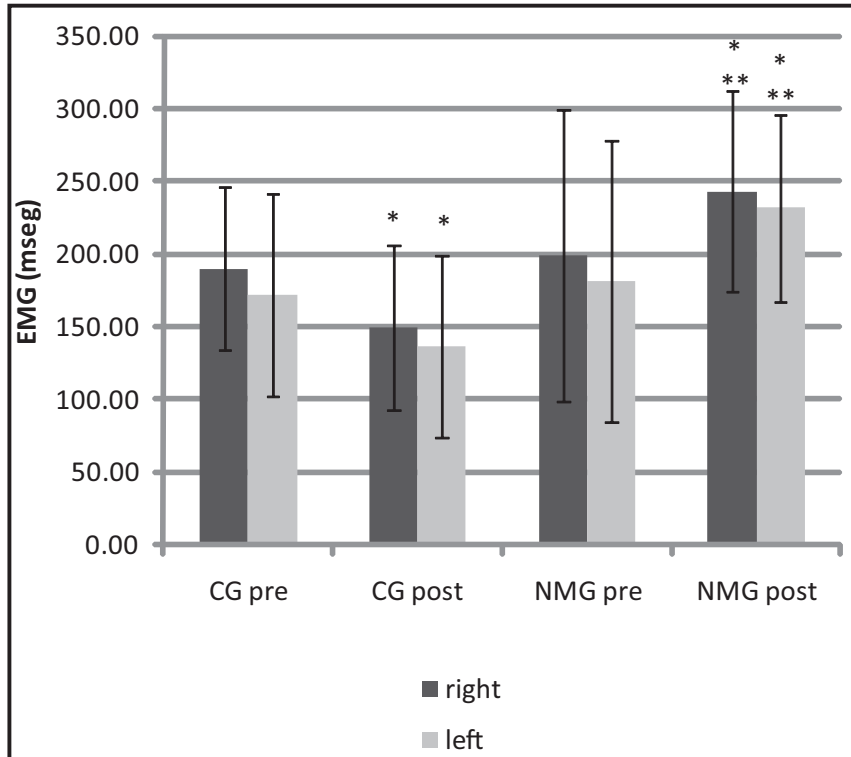

${ }^{*} \mathrm{p}<0.05$, pre vs. post. ${ }^{* *} \mathrm{p}<0.05$, NMG post vs, CG post.

EMG: Electromyography, NMG: Neural mobilization group, CG: Control group.

FIGURE 1 - Analysis of the electromyography signal in different groups.

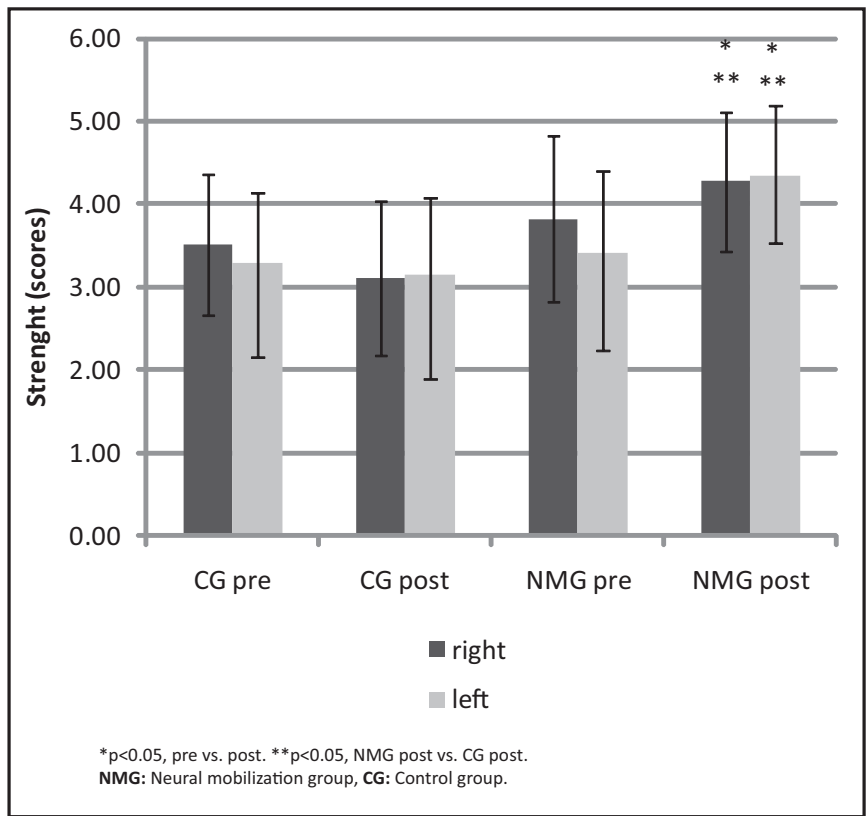

FIGURE 2 - Horizontal extension strength.

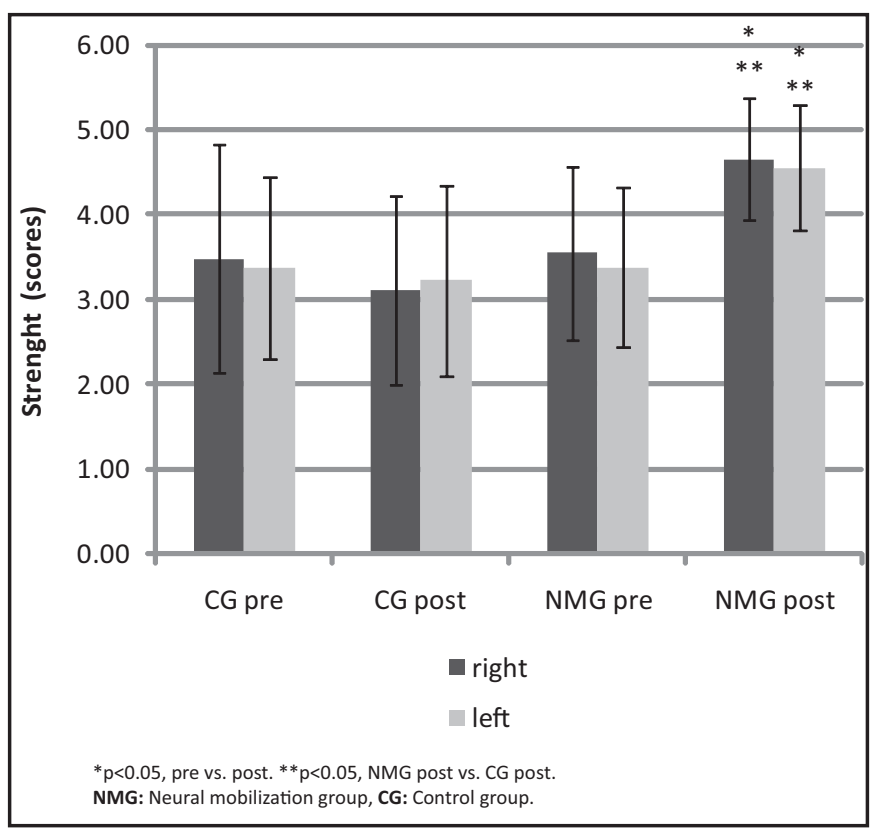

FIGURE 3 - Back flexion strength.

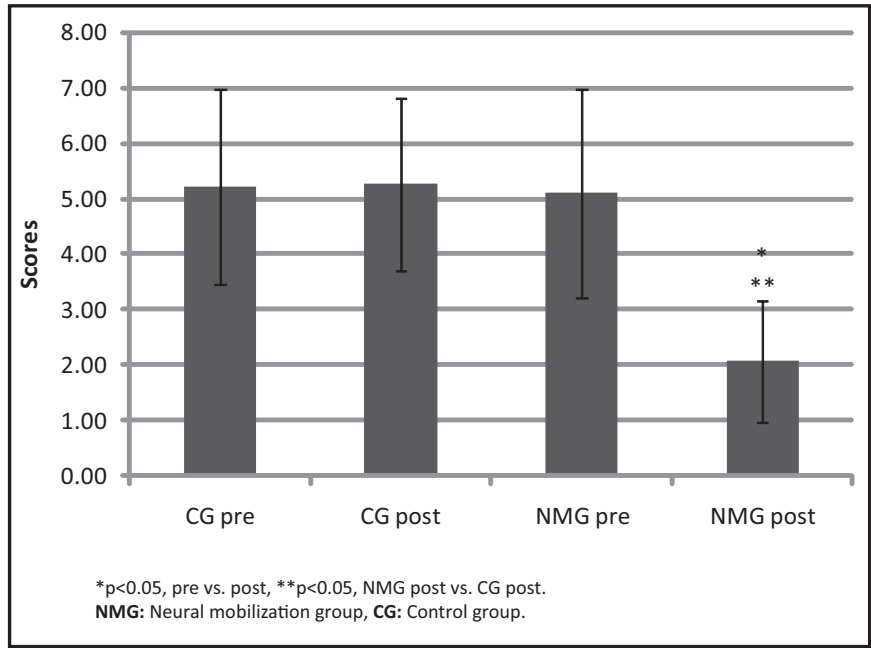

FIGURE 4 - Pain analysis by the visual analogue scale.

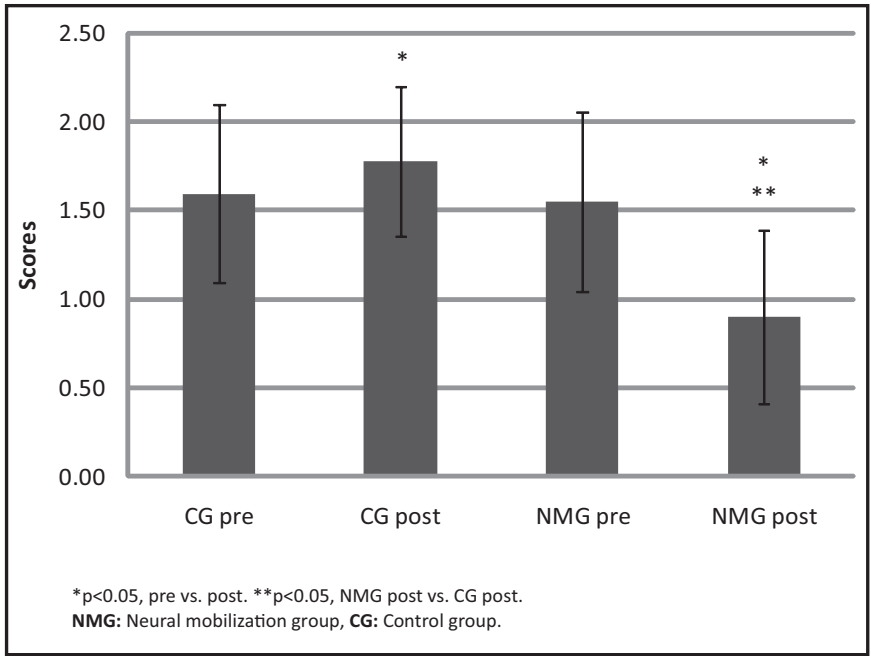

FIGURE 5 - Analysis of disabilty degree. 


\section{DISCUSSION}

The significant reduction in the electromyography signal in both groups and segments in the post-test confirms that both the treatment and the mobilization in conventional physical therapy aid in the functional improvement of leprosy patients. This is consistent with the study of Mora-Brambila et al. ${ }^{28}$, who determined the frequencies of the blink reflex, H-reflex, and motor and sensory nerve conduction alterations in 25 heterogeneous, clinic patients with lepromatous leprosy and a control group of 20 healthy subjects. Their results showed a decrease in the motor and sensory nerve conduction in $40 \%$ and $30 \%$ of patients, respectively.

Brakel et al. ${ }^{29}$ compared the different methods of detecting peripheral neuropathy in leprosy and studied the validity of the monofilament test and the voluntary muscle test (VMT) as the standard tests of nerve function to evaluate electrophysiological response. They found a concordance between the VMT results and the motor nerve conduction, which was found to be beneficial for the ulnar nerve, but very few median or peroneal nerves with abnormal conduction had an abnormal VMT. The NMG in the present study showed an improvement in the nerve function.

Cross $^{30}$ emphasized the domain of prevention of disability and concluded that the preservation of peripheral nerve function is primarily dependent on early detection; as a result of challenges that may compromise the peripheral nerve function, it is suggested that a sharper focus be given to the interventions that prevent secondary disabilities. The paradox of these pragmatic and simple interventions is that they are often difficult to implement.

It is important to note that the electrophysiological assessments have identified household contacts of leprosy patients who have impaired nerve conduction and autonomic nerve function but no clinical symptoms. Novel techniques such as nerve imaging should be utilized in these studies, although the application of such technology for leprosy is still in the developmental stage $e^{4}$.

The presence of muscle atrophy in leprosy has three grades: strong, weak, and paralysed ${ }^{4}$. The lower motor neuron involvement manifests as weakness, atrophy, cramps, and fasciculations. Stiffness and slowness of movement are common manifestations of upper motor neuron involvement ${ }^{31}$.

The fact that muscle strength increased in both segments in the NMG after the treatment demonstrates the effectiveness of the technology used to maintain and increase muscle strength, whereas muscle atrophy is the first sign of a severe impairment of the ulnar nerve ${ }^{32}$. However, Suresh et al..$^{33}$ evaluated the hand muscle weakness detected through dynamometry as an indicator for the changes in motor nerve function detected by voluntary muscle testing of the ulnar and median nerves. They recommended that dynamometry be used as an additional method to monitor the changes in nerve function in leprosy, particularly in subjects with early motor impairment of the ulnar nerve.

Neuritis is considered an important factor in the induction of impairments of leprosy, and it is defined as the presence of pain in a peripheral nerve trunk ${ }^{15}$. The reduction in the perception of pain in the patients undergoing the treatment of neural mobilization in this study indicates an improvement in painful episodes that are characteristic of leprosy.
Van der Heide et al. ${ }^{34}$ found an association between the onset of pain and the onset of trapeziums muscle activity in all painful trials. However, muscle activity was also present in the subjects with no pain.

Afonso Junior ${ }^{35}$ reported that $54 \%$ of respondents had some type of pain. However, Andrade et al. ${ }^{36}$, in their research on the medicinal use of fishery resources by the residents of São Félix, State of Bahia, described a compound produced by marine organisms called tetrodotoxin, which is a water-soluble compound that, when diluted, acts as an extraordinary and narcotic analgesic. Moreover, this compound is found in the liver and reproductive organs of the puffer fish ${ }^{37}$, which are used in Japan for the treatment of neurogenic pain in leprosy and cancer patients ${ }^{38}$.

The degree of disability was significantly reduced in the NMG, which is in agreement with a study by Goulart and colleagues ${ }^{39}$. In that study, the objective indicators that apply to the epidemiological analysis and operational control program of leprosy in Western Sanitary District, Uberlândia-MG, were used to evaluate the physical disabilities of patients as a measure of program quality and estimated prevalence. We analysed the records of 138 leprosy patients diagnosed in the Health Center of the Federal University of Uberlandia (CSE-UFU) from January 1995 to July 2000. At the time of diagnosis, $24 \%$ of the patients had some degree of disability, including grade I, which indicates late diagnosis. At discharge, $68 \%$ of the patients who started treatment at grade 0 stayed at grade 0 ; among those who started at Grade I, $61.5 \%$ maintained their condition, $23.1 \%$ improved to Grade 0 , and $15.4 \%$ had no record.

A study conducted by Lana et al. ${ }^{40}$ from 1992 to 1997 considered the epidemiological situation of leprosy in Belo Horizonte using the analysis of epidemiological and operational indicators, with an emphasis on early diagnosis of disease. They reported 1,217 cases of leprosy, where the detection rates were considered high in the period 1992/1994 and in the middle in 1995/1997. There was a low detection rate for the clinical forms of non-contagious leprosy (15.6\%), including the indeterminate (3.9\%) stage of the disease, with a clear predominance of the infectious forms (84.4\%). It was observed that $5.6 \%$ of the cases focused on children under 15 , and only $39.7 \%$ of cases were diagnosed within 12 months after the first signs of the disease, thus explaining the high percentage of patients diagnosed with the presence of disability at levels 2 and $3(10.6 \%)$. The present study included patients with disability Grades of 1 and 2 pre-treatment, and the group that underwent the neural mobilization technique achieved a significant improvement to Grade 1.

Pimentel et $a l .{ }^{41}$ conducted a study to determine whether the presence of thickened peripheral nerves and/or pain at diagnosis correlates with the occurrence of disabilities in the initial examination and with the subsequent development of neuritis in multibacillary patients during and after MDT; the study included 103 patients with multibacillary leprosy. Detection of the peripheral nerves at diagnosis correlated statistically $(\mathrm{p}<0.005)$ with the occurrence of disabilities and the development of neuritis during and after MDT in the followup (average follow-up time of 64.6 months from diagnosis). Thus, a good examination of the peripheral nerves at diagnosis is necessary, both for greater attention to the disability already present and with respect to the prevention of further disabilities.

In conclusion, it can be stated that the leprosy patients who underwent a mobilization treatment had improvements in neural function and electromyography levels of muscular strength and reductions in the degree of disability and pain. 
Leprosy is one of the major causes of preventable disability, including impairments, problems in activities of daily living, and social exclusion resulting from stigma. Programs and services dealing with leprosy need to improve the coverage of services and procedures for the prevention and rehabilitation of this disease.

\section{CONFLICT OF INTEREST}

The authors declare that there is no conflict of interest.

\section{REFERENCES}

1. Eidt L. Breve história da hanseníase: sua expansão do mundo para as Américas, o Brasil e o Rio Grande do Sul e sua trajetória na saúde pública brasileira. Saude Soc 2004; 13:76-88.

2. Lockwood D, Burns D, Breathnach S, Cox N, Griffiths C. Leprosy. Rook's textbook of dermatology. edition. Boston, MA: Blackwell Publishing; 2004.

3. Scollard D. The biology of nerve injury in leprosy. Lepr Rev 2008; 79:242-253.

4. Van Brakel W, Saunderson P, Shetty V, Brandsma J, Post E, Jellema R, et al. International workshop on neuropathology in leprosy-consensus report. Lepr Rev 2007; 78:416.

5. Araújo M. Hanseníase no Brasil. Rev Soc Bras Med Trop 2003; 36:373-382.

6. Portney L, Roy S. Eletromiografia e testes de velocidade de condução nervosa. O'Sullivan SB, Schmitz TJ Fisioterapia: avaliação e tratamento 4a ed Barueri (SP): Manole 2004; 213-256

7. Garbino JA. O paciente com suspeita de hanseníase primariamente neural. Hansen Int 2007; 32:203-206.

8. Correia CDC, Ataíde Júnior L, Lins OG, Ferreira MLB. Aspectos eletromiográficos preditores da evolução motora de pacientes com neuroesquistossomose. Arq Neuro-Psiquiatr 2007; 65:130-133.

9. Mahmud M, Merlo Á, Gomes I, Becker J, Nora D. Relação entre Tensão Neural Adversa e estudos de Condução Nervosa em Pacientes com Sintomas da Síndrome do Túnel do carpo. Arq Neuro-Psiquiatr 2006; 64:277-282.

10. Shacklock M. Clinical neurodynamics: Elsevier-Butterworth Heinemann; 2007.

11. Alshami A, Souvlis T, Coppieters M. A review of plantar heel pain of neural origin: differential diagnosis and management. Man Ther 2008; 13:103-111.

12. Coppieters M, Butler D. Do 'sliders' slide and 'tensioners' tension? An analysis of neurodynamic techniques and considerations regarding their application. Man Ther 2008; 13:213-221.

13. Ministério da Saúde. Vigilância em Saúde. Brasília: Ministério da Saúde; 2010.

14. Lasry-Levy E, Hietaharju A, Pai V, Ganapati R, Rice ASC, Haanpää M, et al. Neuropathic Pain and Psychological Morbidity in Patients with Treated Leprosy: A Cross-Sectional Prevalence Study in Mumbai. PLoS Negl Trop Dis 2011; 5:e981.

15. World Health Organization. Global leprosy situation, 2010. Wkly Epidemiol Rec 2010; 85:337-348

16. Araújo MG, Gonçalves DU, Nobre V, Ribas JGR, Carneiro-Proietti ABF, Lambertucci JR, et al. HTLV-1 associated myelopathy diagnosed during lepromatous leprosy reaction treatment: a case report. Rev Soc Bras Med Trop 2010; 43:465-466.

17. Moschioni C, Antunes CMF, Grossi MAF, Lambertucci JR. Risk factors for physical disability at diagnosis of 19,283 new cases of leprosy. Rev Soc Bras Med Trop 2010; 43:19-22.

18. Mastrangelo G, Scoizzato L, Fadda E, Silva GV, Santos LJ, Cegolon L. Epidemiological pattern of leprosy in an endemic area of North-East Brazil, 1996-2005: the supporting role of a Nongovernmental Organization. Rev Soc Bras Med Trop 2009; 42:629-632.

19. Ministério da Saúde. Guia para o Controle da Hanseníase. Brasília: Ministério da Saúde; 2002.

20. Hermens H, Freriks B, Merletti R, Stegeman D, BlokJ, Rau G, et al. SENIAM 8: European recommendations for surface electromyography. Roessingh Research and Development; 1999.
21. Alberton C, Silva E, Cadore E, Coertjens M, Beyer P, Marocco L, et al. Respostas eletromiográficas induzidas pelo isolamento e pela imersão sobre os eletrodos de superfície. Rev Port Cien Desp 2008; 8:330-336.

22. Guanilo M, Rossi L, Dantas R, Kimura M. Burns Specific Pain Anxiety ScaleBSPAS: adaptação transcultural e validação preliminar. 2005.

23. Butler D. Mobilização do sistema nervoso. Tradução de Juliana Frare. Barueri Manole; 2003.

24. Maitland G, Hengered E, Banks K, English K. Manipulação vertebral de Maitland. Rio de Janeiro: Medsi; 2003.

25. Shacklock M. Improving application of neurodynamic (neural tension) testing and treatments: A message to researchers and clinicians. Man Ther 2005; 10:175-179.

26. Dantas EHM, Salomão PT, Vale RGS, Achour Júnior A, Simão R, Figueiredo NMA Scale of perceived exertion in the flexibility (PERFLEX): A dimensionless tool to evaluate the intensity? Fit Perf J 2008; 7:289-294.

27. World Medical Association (WMA). Declaration of Helsinki 2008. Principles for Medical Research Involving Human Subjects. Seoul: 59 th $^{\text {th }}$ MA General Assembly; 2008.

28. Mora-Brambila A, Trujillo-Hernandez B, Coll-Cardenas R, Huerta M, Trujillo X, Vasquez C, et al. Blink reflex, $\mathrm{H}$-reflex and nerve-conduction alterations in leprosy patients. Lepr Rev 2006; 77:114.

29. Van Brakel W, Nicholls P, Das L, Barkataki P, Maddali P, Lockwood D, et al. The INFIR Cohort Study: assessment of sensory and motor neuropathy in leprosy at baseline. Lepr Rev 2005; 76:277.

30. Cross $\mathrm{H}$. The prevention of disability for people affected by leprosy: whose attitude needs to change? Lepr Rev 2007; 78:321.

31. Brooks B, Miller R, Swash M, Munsat T. El Escorial revisited: revised criteria for the diagnosis of amyotrophic lateral sclerosis. Amyotroph Lateral Scler 2000; 1:293-299.

32. Brandsma J, Brakel W. WHO'disability'grading: Operational definitions Lepr Rev 2003; 74:366-373.

33. Suresh M, Nicholls P, Das L, Van Brakel W. Voluntary muscle testing and dynamometry in diagnosis of motor impairment in leprosy: a comparative study within the INFIR Cohort Study. Lepr Rev 2008; 79:277.

34. Van der Heide B, Allison G, Zusman M. Pain and muscular responses to a neural tissue provocation test in the upper limb. Man Ther 2001; 6:154-162.

35. Pimentel Junior PA. Correlação clínico-histopatológica entre dor e invasão perineural nos carcinomas da cabeça e do pescoço [master's thesis]. [Niterói (RJ)]: Fluminense Federal University; 2004. 157 p.

36. Andrade J, Neto C, Medeiros E. Primeiro registro da utilização medicinal de recursos pesqueiros na cidade de São Félix, Estado da Bahia. Acta Sci Biol Sci $2008 ; 27: 177$.

37. Heinrich M, Gibbons S. Ethnopharmacology in drug discovery: an analysis of its role and potential contribution. J Pharm Pharmacol 2001; 53:425-432.

38. Oliver I, Pik A, Britton D, Dangerfield J, Colwell R, Beattie A. Virtual biodiversity assessment systems. Bioscience 2000; 50:441-450.

39. Goulart I, Dias C, Oliveira A, Silva A, Alves R, Quaresemin C, et al. Degree of incapacity: an indicator for hidden prevalence and program quality of leprosy control in a University Health Center in the Uberlândia District. Hansen Int $2002 ; 27: 5-13$.

40. Lana F, Lima R, Araújo M, Fonseca P. Situação epidemiológica da hanseníase no município de Belo Horizonte/MG-Período 92/97. Hansen Int 2000; 25:121-132.

41. Pimentel M, Borges E, Sarno E, NeryJ, Gonçalves R. O exame neurológico inicial na hanseníase multibacilar: correlação entre a presença de nervos afetados com incapacidades presentes no diagnóstico e com a ocorrência de neurites francas. An Bras Dermatol 2003; 78:561-568. 